\title{
Group Decision-Making Method for Dynamic Cloud Model Based on Cumulative Prospect Theory
}

\author{
Xiaoxia Wang, Fengbao Yang, Dawei Li and Feifei Zhang \\ School of Information and Communication Engineering, North University of \\ China, \\ Taiyuan, Shanxi, China \\ wangxiaoxia@nuc.edu.cn
}

\begin{abstract}
Group decision-making is a situation faced when individuals collectively make a choice from the alternatives before them. Aiming to the drawback that not all plans can be evaluated by a single expert during group decision-making process, a group decisionmaking method for dynamic cloud distribution is proposed in this paper based on cumulative prospect theory. First, experts and plans were divided into groups according to the classification rule, and plans were described with the cloud model. The expectation, the entropy and the super entropy decision matrix were structured respectively. Then, the maximum and minimum values in decision matrix were set as positive and negative reference points. The parameter values of cumulative cloud prospect were calculated and the synthesis prospect values of every group were obtained. Finally, the plans were sorted based on the mean of synthesis prospect values for every group, and illustrated by specific examples. The ranking results show that the proposed method is rationality and practicability. So the proposed method can be widely used in group decision-making of grouping scheme or grouping expert.
\end{abstract}

Keywords: Dynamic group decision-making; Cumulative prospect theory; Cloud model; Comprehensive prospect value

\section{Introduction}

As modern science and technology develops rapidly, people start to pay more and more attention to group decision-making methods, which have important applicable values and developmental prospects in many fields such as investment decision-making, intelligent transportation and network planning, etc., [1-2]. Group decision-making methods mainly contain multiple attribute decision making(MADM) and multiple objective decision making(MODM), in which the former primarily makes a decision about the known solution and the latter produces a scheme about unknown solution [3-5]. Before using these two kinds of group decision-making methods, experts must evaluate all solutions. But actually with the increase number of solutions and experts, it is impossible for all experts to evaluate every solution. Furthermore, considering the effect of external factors and conditions, the value of each factor which was used to group decision-making is uncertain. Therefore, as experts and solutions are divided into different groups, this has important practical value to research how the plans are ordered in the group whose value factors are uncertain.

At present, there are many researches focusing on group decision-making methods. For instance, delphi method researches some ways to solve the problems of group decisionmaking by several rounds of discussion [6]; Jian Huang et. al., put forward a novel model of group decision-making with the help of FDAHP[7]; Xiaopeng Zhang et. al., researched the performance problems about dynamic group decision-making by means of the view of 
dynamics [8]. Despite the benefits of these researches, most of them were based on the conditions that all experts had already know the evaluations of all solutions. And in the practical process of decision-making, experts, who are effected by some factors such as personal experiences, attitudes to the problem and personal habits, may have subjective preference or disgust for different solutions, and this can effects final decision-making results. Therefore, it is necessary to take the preference of decision makers into account in group decision-making.

For this purpose, to solve the problem that part of the evaluations are unknown and property values are given in the form of cloud model, this paper proposes a novel method of group decision-making based on Cumulative Prospect Theory. The rationality and practicability of proposed method has been illustrated by specific examples.

\section{Basic Knowledge}

\subsection{Cumulative Prospect Theory}

Cumulative Prospect Theory is an uncertain decision-making theory that based on the hypothesis of bounded rationality, and it was proposed by Kahneman and Tversky in the view of prospect theory. This method can adapt to human's thinking modes in contrast with expected utility theory which is fully rational [9]. Cumulative Prospect Theory mainly considers gains and losses of problems. In other words, people usually use "risk reversion" measurement when facing profits. But when facing losses, people usually use some "risk seeking" measurement. The prospect value $V$ is mainly decided by value function $v$ and the accumulated weight function $\pi$. As it is followed:

$V(f)=V\left(f^{+}\right)+V\left(f^{-}\right)=\sum_{i=0}^{n} v\left(x_{i}\right) \pi_{i}^{+}+\sum_{i=0}^{n} v\left(x_{i}\right) \pi_{i}^{-}$

Where $i$ is profit value and when $i \geq 0, i$ represents profits, so $\pi_{i}=\pi_{i}^{+}$; When $i<0, i$ represents losses, so $\pi_{i}=\pi_{i}^{-}$.

The value function can effectively describe the feature that decision makers prefer to avoid risks while facing profits and seek risks while facing losses, which is followed:

$v(x)=\left\{\begin{array}{cc}x^{\alpha} & x \geq 0 \\ -\lambda(-x)^{\beta} & x<0\end{array}\right.$

Where $x$ is the difference between solutions and reference point. When $x \geq 0$, it presents profits; when $x<0$, it represents losses. $\alpha \in[0,1]$ is the risk preference coefficient. $\beta \in[0,1]$ is the risk aversion coefficient. When $\alpha=\beta=1$, both of them are risk neutral. $\lambda$ is the avoiding loss coefficient. when $\lambda>1$, decision makers will be more sensitive to losses.

\subsection{Cloud Model}

At 1995, Deyi Li proposed the cloud model, which realizes the conversion from qualitative to quantitative of uncertainty information [10-11]. It is expressed as follows:

Definition 1(Cloud Model [10]): A random realization of a qualitative concept of $C$ in domain $U$ is $x \in U$. If the certainty of to $C$ is $\mu(x) \in[0,1]$, then the distribution of $x$ in domain $U$ is in cloud form, in which $\mu(x)$ is a random number with certain stability. And the distribution is expressed as $C(X) . x$ is named as cloud droplet.

There are 4 basic properties for cloud model as follows:

(i)For any cloud droplet $x$ in domain $U$, the mapping of $x$ to interval [0-1] is essentially a one-to-many transformation;

(ii) $\mu(x)$ is a random number with a certain probability distribution; 
(iii) $x$ is out of order. The more cloud droplets, the better the expression of the overall characteristics of qualitative concept;

(vi)Both the probability that $x$ appear and its contributions for concepts are proportional to certainty.

Cloud model describes the uncertainty of $C$ by using expectation, entropy and hyper entropy, where the expectation is the most typical sample value; entropy is uncertainty; hyper entropy is the aggregation level of cloud droplet $x$.

\section{Methodology}

\subsection{The Description of Problems about Group Decision-Making}

If there are $m$ groups of cloud model, and the $k$ th plan group is $O_{k}=\left\{o_{1 k}, o_{2 k}, \cdots, o_{l k}\right\}$.where $1 \leq k \leq m$. The attribute set of group $k$ is $A_{k}=\left\{a_{1 k}, a_{2 k}, \cdots, a_{q k}\right\}$, in which each element is independent; $w_{k}=\left\{w_{1 k}, w_{2 k}, \cdots, w_{q k}\right\}$ is weight vector and it meets $0 \leq w_{j k} \leq 1$ and $\sum_{j=1}^{q} w_{j k}=1$.Decision-makers need to evaluate each attribute in every solution and describe attributes with cloud membership. So the attribute value vector in solution ${ }^{t}$ is represented as follows:

$$
\mu\left(A_{t}\right)=\left\{\mu\left(a_{1 t}\right), \mu\left(a_{2 t}\right), \cdots, \mu\left(a_{q t}\right)\right\}
$$

Where $1 \leq t \leq l$.

\subsection{The Steps of Dynamic Group Decision-Making}

According to the problems described in 3.1, the specific steps of group decisionmaking method for dynamic cloud model based on cumulative prospect theory are represented as follows:

(i)According to the actual condition, attributes $A_{i k}$ and weight values $w_{i k}$ of each solution in the $k$ th group in cloud model form are provided, where $0 \leq w_{i k} \leq 1, i \in[1, q]$, $k \in[1, m]$. Then attributes are normalized through the method in reference [12], average value $E_{k}$, entropy $E n_{k}$ and hyper entropy $H c_{k}$ are calculated and weighted cloud decision matrix $\left[E_{k}\right],\left[E n_{k}\right]$ and $\left[H c_{k}\right]$ are obtained;

(ii)The maximum and minimum values in weighed cloud decision matrix represent positive and negative reference points respectively, as follows:

$\left\{\begin{array}{l}R_{k}^{+}=\max \left[R_{k}\right] \\ R_{k}^{-}=\min \left[R_{k}\right]\end{array}\right.$

Where $R$ represents average $E$, entropy $E n$ and hyper entropy $H c$ respectively.

Then the distance between positive and negative reference points is calculated:

$\left\{\begin{array}{l}D\left(R_{k}^{+}\right)=\sqrt{\sum_{i=1}^{q}\left[\left(R_{i k}-R_{k}^{+}\right) \cdot w_{i}\right]^{2}} \\ D\left(R_{k}^{-}\right)=\sqrt{\sum_{i=1}^{q}\left[\left(R_{i k}-R_{k}^{-}\right) \cdot w_{i}\right]^{2}}\end{array}\right.$

(iii) Cumulative cloud prospect values of each parameter in the $k$ th group are calculated according to Formula (1) and (2). As follows:

$V_{R_{k}}(x)=\left[D\left(R_{k}^{+}\left(x_{i}\right)\right)\right]^{\alpha} \cdot \pi_{i}^{+}-\lambda\left[-D\left(R_{k}^{-}\left(x_{i}\right)\right)\right]^{\beta} \cdot \pi_{i}^{-}$ 
$\left\{\begin{array}{l}\pi_{i}^{+}=\frac{D\left(R_{k}^{+}\right)}{D\left(R_{k}^{+}\right)+D\left(R_{k}^{-}\right)} \\ \pi_{i}^{-}=\frac{D\left(R_{k}^{-}\right)}{D\left(R_{k}^{+}\right)+D\left(R_{k}^{-}\right)}\end{array}\right.$

Therefore, the results obtained from reference [13] are used that $\alpha=\beta=0.88$ and $\lambda=2.25$, comprehensive prospect values of each solution are obtained:

$V_{k}=\sqrt[3]{V_{E_{k}}(x) \times V_{E n_{k}}(x) \times V_{H c_{k}}(x)}$

(iv) $m$ groups are sorted according to the mean values of comprehensive prospect value, and recorded as $L=\left\{L_{1}, L_{2}, \cdots, L_{m}\right\}$.In the meantime, solutions in the $k$ th group are sorted according to comprehensive prospect value, and they are recorded as $O_{k}^{\prime}=\left\{o_{1 k}^{\prime}, o_{2 k}^{\prime}, \cdots, o_{l k}^{\prime}\right\}$. Finally, a solution with the biggest comprehensive prospect value in solution group $L_{1}$ is selected and is regarded as the best solution;

(v) The solution with second biggest comprehensive prospect value is selected from solution group $L_{1}$, and it is contrasted with the best solution in $L_{2}$. If former is greater than latter, the former is regarded as the second best solution. Otherwise, the solution that has the biggest comprehensive prospect value in $L_{2}$ is set as the second best solution;

(vi) If the former solution in step (iv) works out, then compare the solution that has the third biggest comprehensive prospect value to the solution from $L_{1}$ that has the biggest comprehensive prospect value from $L_{2}$.If the former solution is greater than the latter one, the former will be the third best solution; If the latter solution in step (iv) works out, we will mutually compare the second biggest comprehensive prospect value in $L_{1}$ and $L_{2}$ to the biggest comprehensive prospect value in $L_{3}$, and then the biggest one is the third best solution; By parity of reasoning, it comes to an end until all solutions are compared.

\section{Result Analysis and Discussion}

For instance, in an investment engineering project, a company plans to develop 9 new services to enlarging business which are $X_{1}, X_{2}, X_{3}, X_{4}, X_{5}, X_{6}, X_{7}, X_{8}, X_{9}$. And they invite 3 investment companies to do a risk assessment to 3 new services before investing. Suppose that three investment companies evaluate them according to 4 attribute indicators, including return time $A_{1}$, risk possibility $A_{2}$, investment strength $A_{3}$ and income $A_{4}$. $A_{1}, A_{2}$ and $A_{3}$ are cost type attribute indexes; $A_{4}$ is profits attribute index. Weight coefficients of attribute indexes are shown in Table 1.

Table 1. Weight Coefficient of Attribute Indexes

\begin{tabular}{|c|l|l|l|l|}
\hline $\begin{array}{c}\text { attribute } \\
\text { indexes }\end{array}$ & $A_{1}$ & $A_{2}$ & $A_{3}$ & $A_{4}$ \\
\hline weight & 0.20 & 0.25 & 0.25 & 0.3 \\
\hline
\end{tabular}

For convenient calculation, supposing that when three investment companies $S_{1}, S_{2}$ and $S_{3}$ assess new services, they will give attribute values in form of Triangular cloud distribution, as shown in Table 2. 
Table 2. Triangular Cloud Distribution of Nine New Businesses from Three Investment Companies

\begin{tabular}{|c|c|c|c|c|c|}
\hline \multicolumn{2}{|c|}{$\begin{array}{l}\text { bute } \\
\text { new business }\end{array}$} & $A_{1}$ & $A_{2}$ & $A_{3}$ & $A_{4}$ \\
\hline \multirow[t]{3}{*}{$S_{1}$} & $X_{1}$ & $\begin{array}{c}{[0.35,0.40,0.43} \\
]\end{array}$ & $\begin{array}{c}{[0.42,0.48,0.50} \\
]\end{array}$ & $\begin{array}{c}{[0.27,0.34,0.40} \\
]\end{array}$ & $\begin{array}{c}{[0.85,0.90,0.93} \\
]\end{array}$ \\
\hline & $X_{2}$ & $\begin{array}{c}{[0.28,0.34,0.38} \\
]\end{array}$ & $\begin{array}{c}{[0.30,0.35,0.38} \\
]\end{array}$ & $\begin{array}{c}{[0.30,0.34,0.36} \\
]\end{array}$ & $\begin{array}{c}{[0.90,0.95,0.97} \\
]\end{array}$ \\
\hline & $X_{3}$ & $\begin{array}{c}{[0.32,0.40,0.45} \\
]\end{array}$ & $\begin{array}{c}{[0.45,0.48,0.50} \\
]\end{array}$ & $\begin{array}{c}{[0.25,0.30,0.35} \\
]\end{array}$ & $\begin{array}{c}{[0.89,0.93,0.96} \\
]\end{array}$ \\
\hline \multirow[t]{3}{*}{$S_{2}$} & $X_{4}$ & $\begin{array}{c}{[0.30,0.38,0.43} \\
]\end{array}$ & $\begin{array}{c}{[0.45,0.50,0.55} \\
]\end{array}$ & $\begin{array}{c}{[0.14,0.18,0.20} \\
]\end{array}$ & $\begin{array}{c}{[0.91,0.93,0.95} \\
]\end{array}$ \\
\hline & $X_{5}$ & $\begin{array}{c}{[0.18,0.24,0.30} \\
]\end{array}$ & $\begin{array}{c}{[0.35,0.37,0.39} \\
]\end{array}$ & $\begin{array}{c}{[0.24,0.28,0.30} \\
]\end{array}$ & $\begin{array}{c}{[0.90,0.93,0.95} \\
]\end{array}$ \\
\hline & $X_{6}$ & $\begin{array}{c}{[0.15,0.20,0.25} \\
]\end{array}$ & $\begin{array}{c}{[0.51,0.54,0.58} \\
]\end{array}$ & $\begin{array}{c}{[0.32,0.35,0.35} \\
]\end{array}$ & $\begin{array}{c}{[0.87,0.90,0.93} \\
]\end{array}$ \\
\hline \multirow[t]{3}{*}{$S_{3}$} & $X_{7}$ & $\begin{array}{c}{[0.16,0.20,0.25} \\
]\end{array}$ & $\begin{array}{c}{[0.35,0.38,0.40} \\
]\end{array}$ & $\begin{array}{c}{[0.20,0.25,0.28} \\
]\end{array}$ & $\begin{array}{c}{[0.93,0.95,0.97} \\
]\end{array}$ \\
\hline & $X_{8}$ & $\begin{array}{c}{[0.14,0.20,0.25} \\
]\end{array}$ & $\begin{array}{c}{[0.30,0.34,0.36} \\
]\end{array}$ & $\begin{array}{c}{[0.21,0.24,0.28} \\
]\end{array}$ & $\begin{array}{c}{[0.95,0.97,0.99} \\
]\end{array}$ \\
\hline & $X_{9}$ & $\begin{array}{c}{[0.24,0.28,0.30} \\
]\end{array}$ & $\begin{array}{c}{[0.26,0.30,0.32} \\
]\end{array}$ & $\begin{array}{c}{[0.30,0.35,0.40} \\
]\end{array}$ & $\begin{array}{c}{[0.85,0.87,0.90} \\
]\end{array}$ \\
\hline
\end{tabular}

Then, we need to standardize intuitive and fuzzy clouds decision matrix by means of the method in reference [12], and the attribute values of standardization are shown in Table 3.

Table 3. The Attribute Values of Standardization

\begin{tabular}{|c|c|c|c|c|c|}
\hline \multicolumn{2}{|c|}{ attribute } & $A_{1}$ & $A_{2}$ & $A_{3}$ & $A_{4}$ \\
\hline \multirow{3}{*}{$S_{1}$} & $X_{1}$ & {$[0.81,0.88,1.0]$} & {$[0.84,0.88,1.0]$} & {$[0.68,0.79,1.0]$} & {$[0.91,0.97,1.0]$} \\
\cline { 2 - 6 } & $X_{2}$ & {$[0.74,0.82,1.0]$} & {$[0.79,0.86,1.0]$} & {$[0.83,0.88,1.0]$} & {$[0.93,0.98,1.0]$} \\
\cline { 2 - 6 } & $X_{3}$ & {$[0.71,0.80,1.0]$} & {$[0.90,0.94,1.0]$} & {$[0.71,0.83,1.0]$} & {$[0.93,0.97,1.0]$} \\
\hline \multirow{3}{*}{$S_{2}$} & $X_{4}$ & {$[0.70,0.79,1.0]$} & {$[0.82,0.90,1.0]$} & {$[0.70,0.78,1.0]$} & {$[0.96,0.98,1.0]$} \\
\cline { 2 - 6 } & $X_{5}$ & {$[0.60,0.75,1.0]$} & {$[0.90,0.95,1.0]$} & {$[0.80,0.86,1.0]$} & {$[0.95,0.98,1.0]$} \\
\cline { 2 - 6 } & $X_{6}$ & {$[0.60,0.75,1.0]$} & {$[0.88,0.94,1.0]$} & {$[0.91,0.91,1.0]$} & {$[0.94,0.97,1.0]$} \\
\hline \multirow{3}{*}{$S_{3}$} & $X_{7}$ & {$[0.64,0.80,1.0]$} & {$[0.88,0.92,1.0]$} & {$[0.71,0.80,1.0]$} & {$[0.96,0.98,1.0]$} \\
\cline { 2 - 6 } & $X_{8}$ & {$[0.56,0.70,1.0]$} & {$[0.83,0.88,1.0]$} & {$[0.75,0.88,1.0]$} & {$[0.96,0.98,1.0]$} \\
\cline { 2 - 6 } & $X_{9}$ & {$[0.80,0.86,1.0]$} & {$[0.81,0.87,1.0]$} & {$[0.75,0.86,1.0]$} & {$[0.94,0.97,1.0]$} \\
\hline
\end{tabular}

Calculate weighted clouds decision matrix:

$$
\begin{gathered}
{\left[E_{1}\right]=\left[\begin{array}{llll}
0.349 & 0.443 & 0.390 & 0.575 \\
0.326 & 0.427 & 0.439 & 0.304 \\
0.318 & 0.467 & 0.391 & 0.577
\end{array}\right],\left[E_{2}\right]=\left[\begin{array}{llll}
0.314 & 0.468 & 0.389 & 0.586 \\
0.290 & 0.471 & 0.428 & 0.584 \\
0.290 & 0.490 & 0.458 & 0.585
\end{array}\right],} \\
{\left[E_{3}\right]=\left[\begin{array}{llll}
0.328 & 0.458 & 0.397 & 0.586 \\
0.296 & 0.438 & 0.397 & 0.586 \\
0.342 & 0.432 & 0.422 & 0.579
\end{array}\right],}
\end{gathered}
$$




$$
\begin{aligned}
& {\left[E n_{1}\right]=\left[\begin{array}{llll}
0.162 & 0.241 & 0.282 & 0.165 \\
0.143 & 0.156 & 0.165 & 0.300 \\
0.138 & 0.176 & 0.144 & 0.172
\end{array}\right],\left[E n_{2}\right]=\left[\begin{array}{llll}
0.137 & 0.150 & 0.141 & 0.171 \\
0.118 & 0.175 & 0.183 & 0.172 \\
0.118 & 0.161 & 0.183 & 0.172
\end{array}\right],} \\
& {\left[E n_{3}\right]=\left[\begin{array}{llll}
0.117 & 0.181 & 0.103 & 0.171 \\
0.080 & 0.165 & 0.129 & 0.171 \\
0.154 & 0.161 & 0.145 & 0.171
\end{array}\right]} \\
& {\left[H c_{1}\right]=\left[\begin{array}{llll}
0.083 & 0.088 & 0.076 & 0.102 \\
0.078 & 0.056 & 0.089 & 0.180 \\
0.056 & 0.065 & 0.066 & 0.132
\end{array}\right],\left[H c_{2}\right]=\left[\begin{array}{llll}
0.074 & 0.042 & 0.078 & 0.131 \\
0.030 & 0.023 & 0.062 & 0.132 \\
0.030 & 0.036 & 0.044 & 0.132
\end{array}\right],} \\
& {\left[H c_{3}\right]=\left[\begin{array}{llll}
0.051 & 0.078 & 0.011 & 0.132 \\
0.023 & 0.072 & 0.026 & 0.132 \\
0.039 & 0.045 & 0.067 & 0.132
\end{array}\right]}
\end{aligned}
$$

The maximum and minimum values in weighted clouds decision matrix represent positive and negative reference points respectively.

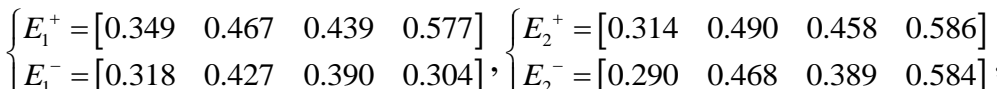

$$
\begin{aligned}
& \left\{\begin{array}{llll}
E_{3}^{+} & =\left[\begin{array}{llll}
0.342 & 0.458 & 0.422 & 0.586
\end{array}\right] \\
E_{3}^{-} & =\left[\begin{array}{llll}
0.296 & 0.432 & 0.397 & 0.586
\end{array}\right]
\end{array}\right. \\
& \left\{E n_{1}^{+}=\left[\begin{array}{llll}
0.162 & 0.241 & 0.282 & 0.300
\end{array}\right]\left\{E n_{2}^{+}=\left[\begin{array}{llll}
0.138 & 0.175 & 0.183 & 0.172
\end{array}\right]\right.\right. \\
& E n_{1}^{-}=\left[\begin{array}{llll}
0.138 & 0.156 & 0.144 & 0.165
\end{array}\right],\left\{E n_{2}^{-}=\left[\begin{array}{llll}
0.118 & 0.150 & 0.141 & 0.171
\end{array}\right]\right. \text {, }
\end{aligned}
$$

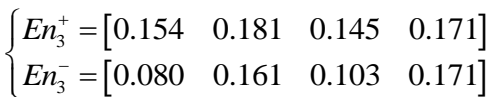

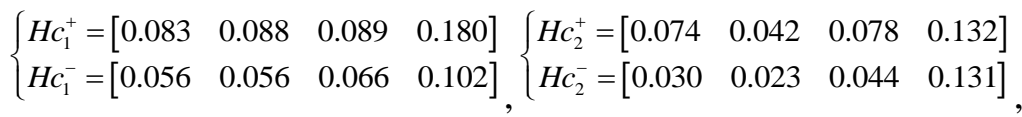

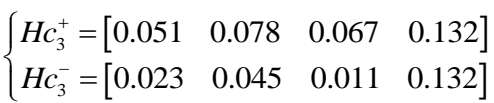

The distances from each solution to positive and negative reference points are calculated through Formula (5) as shown in Table 4.

Table 4. Distance of Each Alternative from the Positive and Negative Ideal Solution

\begin{tabular}{|c|c|c|c|c|c|c|}
\hline & $D\left(E_{1}^{+}\right)$ & $D\left(E_{1}^{-}\right)$ & $D\left(E n_{1}^{+}\right)$ & $D\left(E n_{1}^{-}\right)$ & $D\left(H c_{1}^{+}\right)$ & $D\left(H c_{1}^{-}\right)$ \\
\hline$X_{1}$ & 0.0137 & 0.0814 & 0.0405 & 0.0405 & 0.0236 & 0.0084 \\
\hline$X_{2}$ & 0.0825 & 0.0123 & 0.0362 & 0.0408 & 0.0080 & 0.0093 \\
\hline$X_{3}$ & 0.0120 & 0.0825 & 0.0541 & 0.0054 & 0.0165 & 0.0093 \\
\hline & $D\left(E_{2}^{+}\right)$ & $D\left(E_{2}^{-}\right)$ & $D\left(E n_{2}^{+}\right)$ & $D\left(E n_{2}^{-}\right)$ & $D\left(H c_{2}^{+}\right)$ & $D\left(H c_{2}^{-}\right)$ \\
\hline$X_{4}$ & 0.0181 & 0.0034 & 0.0122 & $\begin{array}{c}1.4440 \mathrm{e}- \\
005\end{array}$ & $\begin{array}{c}3.0000 \mathrm{e}- \\
004\end{array}$ & 0.0097 \\
\hline$X_{5}$ & 0.0090 & 0.0098 & $\begin{array}{c}1.600 \mathrm{e}- \\
005\end{array}$ & 0.0122 & 0.0063 & 0.0045 \\
\hline$X_{6}$ & $\begin{array}{c}2.3040 \mathrm{e}- \\
005\end{array}$ & 0.0181 & 0.0035 & 0.0109 & 0.0086 & 0.0033 \\
\hline$X_{7}$ & $D\left(E_{3}^{+}\right)$ & $D\left(E_{3}^{-}\right)$ & $D\left(E n_{3}^{+}\right)$ & $D\left(E n_{3}^{-}\right)$ & $D\left(H c_{3}^{+}\right)$ & $D\left(H c_{3}^{-}\right)$ \\
\hline$X_{8}$ & 0.0063 & 0.0258 & 0.0105 & 0.0049 & 0.0140 & 0.0082 \\
\hline$X_{9}$ & 0.0068 & 0.0015 & 0.0058 & 0.0066 & 0.0104 & 0.0077 \\
\hline
\end{tabular}


Comprehensive prospect values of each solution were obtained by means of Formula (6) and (7), and three groups are sorted by means of the Step (4) to (6) in section of 3.2 as shown in Table 5.

Table 5. Comprehensive Cloud Prospect Values and Ranking Result of Alternatives

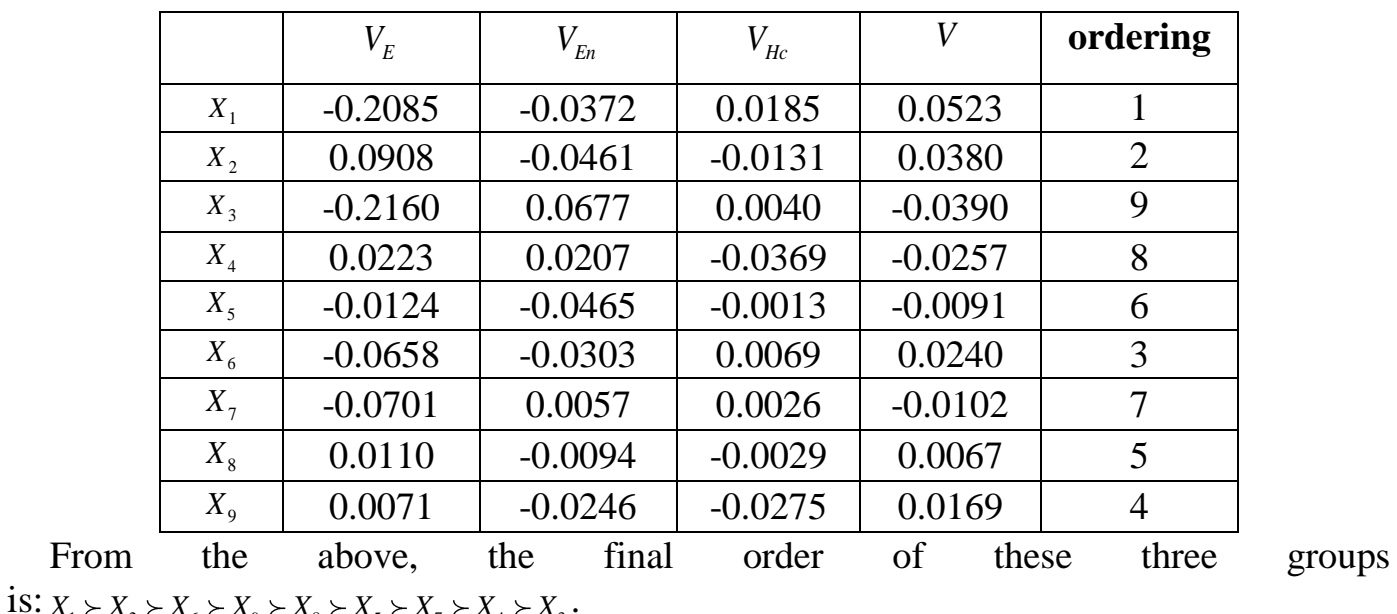

\section{Conclusions}

This paper proposed a multi-attribute group decision-making method for attribute values is cloud distribution and each expert is unable to assess all solutions according to cumulative prospect. Experts and solutions are classified with grouping rules and decision-making matrix is constructed by expectation, entropy and hyper entropy of cloud distribution. The value function is constructed with positive and negative reference points, then comprehensive cloud prospect values are obtained and plans are put in ordered. The experiment results show that the advantages of proposed method as follow:

(i) Comprehensive cloud prospect values are calculated by expectation, entropy and hyper entropy of cloud distributions. These properties not only describe randomness and fuzziness of uncertain information, but also give comprehensive cloud prospect values which make decision-making results more comprehensive and reasonable, and can decline investment risks effectively;

(ii) Proposed method can be applied in these situations: when only parts of the solution are evaluated by some experts and when all solutions are evaluated by each expert.

Further research based on this method is necessary, especially for investment decisionmaking, intelligent transportation and network planning.

\section{Acknowledgements}

This paper is supported by the National Natural Science Foundation of China (Nos. 61171057, 61503345), Science Foundation for North University of China (No.110246), Specialized Research Fund for Doctoral Program of Higher Education of China (No.20121420110004), International Office of Shanxi Province Education Department of China, Basic Research Project in Shanxi Province (Young Foundation). 


\section{References}

[1] S. Wan and J. Dong, "Interval-valued intuitionistic fuzzy mathematical programming method for hybrid multi-criteriagroup decision making with interval-valued intuitionistic fuzzy truth degrees", Information fusion, vol. 26, (2015), pp. 49-65.

[2] B. Sun, M. Wei and J. Du, "Multi-attribute group decision making method of ecological water compensation program based on preference of decision Makers", Journal of coastal research, vol. 73, (2015), pp. 606-610.

[3] C. L. Hwang and K. Yoon, "Multiple attribute decision making", Springer, Berlin, (1981).

[4] B. Liu, Y.Shen and W. Zhang, "An interval-valued intuitionistic fuzzy principal component analysis model-based method for complex multi-attribute large-group decision-making", European journal of operational research, vol. 245, no. 1, (2015), pp. 209-225.

[5] S. Zhang, S. Liu and R. Di, "VIKOR extension methods of dynamic, intuitive, fuzzy and multi-attribute decision-making”, Computer science, vol. 39, no. 2, (2012), pp. 240-243.

[6] A. J. Blow and D. H. Sprenkle, "Common factor across theories of marriage and family therapy: a modified Delphi study", Journal of marital and family theory, vol. 27, no. 3, (2001), pp. 385-401.

[7] J. Huang, J. Lv and Z. Liu, "Dynamic group decision-making and its application based on FAHP", Operations Research and Management Science, vol. 16, no. 1, (2007), pp. 14-18.

[8] X. Zhang, "The performance study of dynamic group decision-making under knowledge sharing and transfer", Master's thesis:South China University of Technology, (2009).

[9] A. Tversky and D. Kahneman, "Advances in prospect theory: cumulative representation of uncertainty", Journal of risk and uncertainty, vol. 5, (1992), pp. 297-323.

[10] D. Li, "Uncertainty artificial intelligence", Beijing:National Defense Industry Press, (2005).

[11] Z. Xu, "Fuzzy Aggregation Operators", IEEE Transactions on fuzzy systems, vol. 15, no. 6, (2007), pp. 1179-1187.

[12] F. Ye and Y. Li, "An extended TOPSIS model based on the possibility theory under fuzzy environment", Knowledge-Based Systems, vol. 67, (2014), pp. 263-269.

[13] A. Tversky and D. Kahneman, "Advances in prospect theory: Cumulative representation of uncertainty", Journal of risk and uncertainty, vol. 5, no. 4, (1992), pp. 297-323.

\section{Authors}

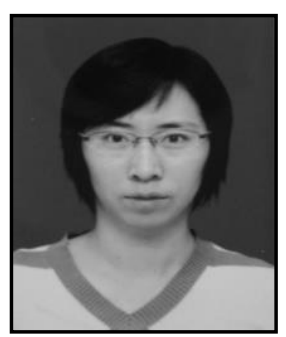

Xiaoxia Wang, Ph.D., lecturer. Research fields: uncertainty reasoning, multi-source information fusion. 